\title{
Efficiency of Two-Stage Technological Innovation in High Patent-Intensive Industries That Considers Time Lag: Research Based on the SBM-NDEA Model
}

\author{
Junzhong Zou $\mathbb{D}^{1,}, 2$ Wei Chen $\mathbb{D}^{1,},{ }^{1}$ Nan Peng $\mathbb{D}^{2},{ }^{2}$ and Xuan Wei $\mathbb{D}^{1}$ \\ ${ }^{1}$ School of Economics and Management, Harbin Engineering University, Harbin 150001, China \\ ${ }^{2}$ East University of Heilongjiang, Harbin 150066, China
}

Correspondence should be addressed to Wei Chen; weichen666@126.com

Received 17 January 2020; Revised 29 March 2020; Accepted 9 April 2020; Published 12 May 2020

Academic Editor: José António Fonseca de Oliveira Correia

Copyright ( 92020 Junzhong Zou et al. This is an open access article distributed under the Creative Commons Attribution License, which permits unrestricted use, distribution, and reproduction in any medium, provided the original work is properly cited.

Considering time lag and accumulation of inputs and outputs, this paper adopts the superefficiency data envelopment analysis (DEA) model to study the technological innovation efficiency of high patent-intensive industries using panel data from 2007 to 2017. Given the characteristics and the actual circumstances of the industries, the innovation process is divided into two stages, and an input-output indicator system is established. The results show that the overall innovation efficiency level of high patent-intensive industries in China is increasing. However, the R\&D achievements in technology are not quickly applied or sufficiently transformed.

\section{Introduction}

With the advance of the economy and technology, knowledge and technological innovation have become major driving forces of economic growth in the 21st century. The United States has proposed the "National Strategic Plan for Advanced Manufacturing," Germany has proposed "German Industry 4.0," and China has proposed the "InnovationDriven Development Strategy" and the "Made in China 2025 Strategy." The "National Intellectual Property Strategy" promulgated in China in 2008 has promoted the development of the nation's patent-intensive industries. In October 2016, the State Intellectual Property Office released the "Statistical Report on the Patent-Intensive Industries in China" and the "Catalogue of Patent-Intensive Industries (for trial implementation)." These publications indicate the national and social focus that has been placed on the development of patent-intensive industries. The two documents also reveal that patent-intensive industries play an increasingly significant role in strengthening China's economic competitiveness and boosting technological and economic development. "Patent-intensive industry" [1] refers to industries in which the intensity and scale of invention patents reach a certain standard that rely on intellectual property rights to participate in market competition and that are in line with innovation-oriented development. Eight industries that exceed the average level of such industries are identified as high patent-intensive industries. These eight industries are pharmaceutical manufacturing, electrical equipment manufacturing, computers and communications equipment manufacturing, and five other industries. According to "China Statistics Yearbook on High Technology Industry" [2], the internal R\&D expenditure of China's patent-intensive industries in 2016 was 291575 million yuan. The number of patent applications was 185913, and the sales of new products totaled 4792424 million yuan. The added value of patent-intensive industries was 15379.6 billion-yuan, accounting for $20.8 \%$ of GDP. Each year, on average, 13420 thousand employment opportunities are created. In China, high patent-intensive industries have become the leading industries of technological advancement and pillar industries of economic development.

From the perspective of previous literatures, much attention has been paid on the study of technological innovation, but there are heterogeneous between different studies 
not only in the results of studies but also in the setting of the statistical models. Hence, a nonparametric model may be a better choice for the study of technological innovation and its impact factors.

Against this backdrop, there are two main purposes and contributions in this research. First, it is imperative to investigate and evaluate the innovation efficiency of the high patent-intensive industries, determine the problems confronted in technological innovation, analyze the factors that affect innovation efficiency in these industries, and establish effective means to improve innovation efficiency in such industries. These measures are of substantial significance to improve the efficiency of technological innovation in high patent-intensive industries. Second, the time lag factor should be considered so that the relationship between impact factors and technological innovation could be more clear, and new policy suggestion could be put forward.

\section{Literature Review}

Several foreign scholars have defined patent intensity and conducted studies on patent-intensive industries. Siwek [3], an American economist, provided the first definition of the "intellectual property industry."

Examining the American pharmaceutical manufacturing industry, Mazzucatoet [4] conducted research on high patent-intensive companies. Among experts, there is no consensus on the concept of technological innovation. Afriat [5] provided the first conceptual description of the efficiency of technological innovation. As research has increased, more scholars have begun to focus on the technological innovation efficiency of high patent-intensive industries. Research topics include the evaluation of technological innovation efficiency, the comparison of technological innovation efficiencies, and the analysis of the factors that affect technological innovation efficiency [6-8].

BangRae Lee, EunSoo Sohn, DongKyu Won, and WoonDong Yeo [9] analyzed the R\&D investment efficiency of 23 industries in the field of precision medicine in South Korea. They found that investment in these technologies can produce good benefits.

Kwangsoo Shin, Eungdo Kim, and EuiSeob Jeong [10] analyzed the relationships among knowledge, innovation ability, technological innovation, and financial performance. They concluded that transformation ability, the connection ability of technological innovation, innovation ability, and absorptive ability have direct and indirect effects on the financial performance of technological innovation.

Eetal [11] applied the DEA model to analyze panel data from 185 regions in 23 European countries and to investigate innovation efficiency in these regions.

Domestic scholars have conducted a series of studies on high patent-intensive industries. Xu and Jiang [12] measured patent-intensive industries based on a combination of research results from home and abroad and studied the R\&D performance of patent-intensive industries in China.

Scholars have adopted various research methods to study innovation efficiency. Pan and Yang [13] used the TOPSIS method and the entropy method to assess patent-intensive industries. Han [14] used stochastic frontier analysis (SFA) to study the technological innovation efficiency of China's high-tech industries. These studies found that the overall innovation efficiency of China's high-tech industries is improving. A number of scholars have employed data envelopment analysis (DEA) to study technological innovation efficiency, successfully analyzing the technological innovation efficiency of high-tech industries using a variety of models. Chen et al. [15] adopted the DEA-Malmquist model, whereas Feng [16] employed the DEA-SBM (data envelopment analysis-slack-based measure) model, which considers undesirable outputs.

To study innovation efficiency, scholars divide the industrial innovation process into different stages. Among such researchers, Jiang [17], Hu, and Zhou [18] regarded the industrial innovation process as one stage. Wen-jing et al. [19] and Bao et al. [20] divided the industrial innovation process into two stages. Liu et al. [7] and Kang et al. [21] divided the industrial innovation process into three stages to measure high patent-intensive industries.

In summary, a considerable number of scholars have studied the technological innovation efficiency of high patent-intensive industries from various aspects. The research on the technological innovation efficiency of such industries has primarily focused on the evaluation of influencing factors and the overall efficiency of technological innovation. Efficiency evaluation of subindustries is rarely conducted, and there is little analysis of the innovation process. In studying innovation efficiency, scholars have adopted various methods, whereby increasingly more researchers have adopted DEA models. Drawing on previous research, this article starts from the innovation process and uses the superslack-based measure network data envelopment analysis model (SBM-NDEA), dividing the technological innovation process into two stages: technological $\mathrm{R} \& \mathrm{D}$ and achievement transformation. With this approach, we can understand the deficiencies in the innovation process of China's patent-intensive industries and establish the breakthrough points for efficient development. Additionally, the SBM-NDEA model with relaxation variables introduced in our approach can better restore the two-stage characteristics of the innovation process.

\section{Research Method}

Data envelopment analysis (DEA) is a new, widely applied and effective nonparametric method to measure technological innovation efficiency. There are two types of DEA. One is the traditional DEA model. The other is the network DEA model. The traditional DEA model does not consider the relationship between decision-making unit (DMU) and input resources and views DMU as a "black box." In contrast, the network DEA model divides the process of technological innovation into several subprocesses, thus transforming the "black box" into a "gray box." Guan and Zuo [22] analyzed innovation efficiency in 35 countries using a two-stage network DEA model. Yu Wenjing, Ma et al. [19] adopted a two-stage serial DEA model to analyze the efficiency of Chinese high-tech enterprises at the 
provincial level. Liu [23] used a three-stage DEA model. Tone and Sahoo et al. [24] introduced variable relaxation as objective function and constructed a superslack-based measure (SBM) model. Liu et al. [25] adopted the superefficiency DEA model to perform a comparative evaluation of the efficiency of S\&T innovation in several Chinese provinces. Chen et al. [26] used a superslack-based measure network data envelopment analysis (SBM-NDEA) model to study the technological innovation efficiency of high patentintensive industries. This model not only considers the problem of variable relaxation but also distinguishes the size of the effective DMU.

In Equation (1), $X_{i}$ is the input of subprocess 1, the number of which is $m$; i.e., $X_{i}=\left(x_{i 1}, x_{i 2}, \ldots, x_{i \mathrm{~m}}\right)$; $f i$ is the output of subprocess 1 , the number of which is $p$; i.e., $f_{i}=\left(f_{i 1}, f_{i 2}, \ldots, f_{i \mathrm{p}}\right)$; $z_{i}$ is the input of subprocess 2 , which includes the outputs of subprocess 1 and additional inputs, the number of which is $q$; i.e., $z_{i}=\left(z_{i 1}, z_{i 2}, \ldots, z_{i q}\right) ; y$ is the output of subprocess 2 , the number of which is $h$; i.e., $y_{i}=\left(y_{i 1}, y_{i 2}, \ldots, y_{i h}\right)$; and $\lambda_{\mathrm{i}}$ is the weight of the $i$ th DMU. Then, the set of production possibilities based on variable returns to scale is as follows:

$$
\left.\frac{P}{\left(X_{0}, Y_{0}\right)}=[X, Y) \mid X \geq \sum_{i \in I, i \neq 0}^{m} \lambda_{i}^{2} Y_{i}, f=\sum_{i=1}^{n} \lambda_{i}^{1} f_{i} ; f=\sum_{i=1}^{n} \lambda_{i}^{2} x_{i}, \lambda \geq 0\right] .
$$

The restriction of intermediate variable $f$ is a free link, which can be changed freely.

The restrictive conditions are as follows:

$$
f \lambda_{1}=f \lambda_{2} .
$$

Based on the preceding assumption, the linear representation of a super-SBM model with variable return is as follows:

$$
E_{0}=\frac{(1 / h) \sum_{i=1}^{h}\left(\bar{y}_{1} / y_{i 0}\right)}{(1 / h) \sum_{i=1}^{p}\left(\bar{f}_{1} / f_{i 0}\right)}
$$

The constraints are as follows:

$$
\begin{aligned}
& \bar{X} \geq \sum_{i \in I, i \neq 0}^{n} \lambda_{i} X_{i}, \\
& \bar{f} \leq \sum_{i \in I, i \neq 0}^{p} \lambda_{i} f_{i}, \\
& \bar{X} \geq X_{0}, \\
& \bar{f} \geq f_{0}, \\
& \bar{f} \leq 0, \\
& \lambda \geq 0 .
\end{aligned}
$$

The efficiency value of each DMU can be greater than 1, and the effective DMUs can be sorted accordingly. Considering the relaxation of input and output variables, Grosskopf and Fare $[25,27]$ regarded the process of technological innovation as an interrelated network, which also includes intermediate variables. The complex and intermediate process from input to output and its model is shown by equation (5). Here, $k$ represents the relative weight of the $k$ th stage of the DMU, and $(i=1,2,3, \ldots, I),(p=1,2, \ldots, P)$, and $(h=1,2, \ldots, H)$ represent the $I$-th input, the $P$-th intermediate variable, and the $H$-th output, respectively. $\alpha$ represents the efficiency value of the technology R\&D stage, $\beta$ represents the efficiency value of the achievements transformation stage, and $f_{p 0}$ represents the best intermediate variable. However, according to Chiu et al. [26, 28], this assumption assumes that all the inputs in the achievements transformation stage come from the outputs in the technology $\mathrm{R} \& \mathrm{D}$ stage without considering the subsequent inputs. Therefore, the model must be modified. The modified model is as follows:

$$
\begin{aligned}
& \min _{\alpha, \beta, \lambda, \mu, \xi} \alpha-\beta, \\
& \text { s.t. } \begin{cases}\sum_{i=1}^{2} \lambda_{k} x_{i j} \leq \alpha x_{i o}, & i=1, \ldots, I, \\
\sum_{j=1}^{2} \lambda_{k} x_{h j} \geq \beta y_{h o}, & h=1, \ldots, H, \\
\sum_{i=1}^{2} \lambda_{k} x_{q j} \geq z_{q o}, & q=1, \ldots, Q, \\
\sum_{i=1}^{2} \lambda_{k} x_{p j} \geq f_{p o}, & p=1, \ldots, P, \\
\sum_{i=1}^{2} \lambda_{k}=1, & \\
\lambda_{k} \geq 0, \alpha \leq 0, \mu_{i} \geq 0, \beta \geq 1,\end{cases}
\end{aligned}
$$

where $f_{p}$ and $z_{q}$ represent the inputs in the technology R\&D stage and the inputs in the achievements transformation stage, respectively. This paper uses the NDEA model to study the technological innovation efficiency of high patent-intensive industries.

\section{Empirical Research}

4.1. Indicator Selection. Based on previous research $[29,30]$ and the purpose of this paper, the innovation process is divided into two subprocesses: the technology R\&D stage and the achievements transformation stage. An input-output indicator system is also constructed (Table 1).

The innovation of labor input is typically based on the number of employees or wage costs. However, it is difficult and inaccurate to obtain the exact level of wage costs in different regions and periods. Regarding the availability and accuracy of the acquired data, this paper adopts the full-time equivalent (FTE) of R\&D personnel for the innovation of labor input.

Therefore, the full-time equivalent (FTE) of R\&D personnel and $\mathrm{R} \& \mathrm{D}$ capital stock are selected as input variables.

It is widely recognized that the output indicators and patents of the R\&D stage are important indications of technological innovation. Patents include invention patents, utility model patents, and design patents. The number of annual patent applications refers to the number of patent applications submitted to and accepted by the State 
TABLE 1: Input and output indicators of technological innovation.

\begin{tabular}{lcc}
\hline Technology R\&D stage & Input indicators & $\begin{array}{c}\text { Full-time equivalent (FTE) of R\&D personnel } \\
\text { R\&D capital stock }\end{array}$ \\
Number of patent applications \\
Achievements transformation stage & Output indicators & $\begin{array}{c}\text { New product development costs } \\
\text { Number of authorized invention patents }\end{array}$ \\
& Input indicators & $\begin{array}{c}\text { Number of patent applications } \\
\text { Number of authorized invention patents } \\
\text { New product sales revenue }\end{array}$ \\
& Output indicators & Number of newly developed projects \\
\hline
\end{tabular}

Intellectual Property Office in a year, which is the basis of R\&D innovation. "Authorized patent" refers to a patent authorized by the State Intellectual Property Office and represents an important achievement of technological innovation.

Therefore, in this paper, the number of patent applications and the number of authorized invention patents are chosen as the output indicators of innovation in the technology R\&D stage.

The input indicators in the achievements transformation stage include the number of patent applications that include output indicators and the number of authorized invention patents in the technology R\&D stage. However, considering other additional inputs, such as the cost of technology import in the stage of achievements transformation, it is more reasonable to count the additional costs as the inputs of new product development costs.

Therefore, in this paper, the input indicators of the achievements transformation stage include new product development costs, number of patent applications, and the number of authorized invention patents.

The output indicators in the achievements transformation stage, the sales revenue of new products, and the number of newly developed projects are the key indicators reflecting the economic benefits of innovative activities of high patent-intensive industries.

On the one hand, the output indicators are used to measure the innovative production capacity. On the other hand, they can reflect the economic value of innovation achievements affected by the market environment and other factors.

Therefore, it is reasonable to adopt the new product sales revenue and the number of newly developed projects as output indicators in the achievements transformation stage.

According to recent research [7,31-33], the input indicators of most studies on the technology R\&D stage primarily include two aspects: capital input innovations and labor input innovations. Capital input innovation has an impact on not only the current period but also the later period due to capital precipitation, which also refers to time lag and accumulation. Thus, if only R\&D expenditure is used as the capital input indicator, innovation efficiency cannot be accurately reflected. Therefore, this paper uses capital stock as an input indicator and adopts the method of perpetual inventory to calculate the R\&D capital stock. Considering the patent application cycle and output cycle, it is assumed that the lag period is one year [34]. The calculation formula is as follows:

$$
U_{i t}=U_{i(t-1)}+(1-\delta) U_{i(t-1)},
$$

where $U_{i t}$ represents the $t$-th R\&D capital stock of the $i$-th DMU and $U_{i(t-1)}$ represents the internal expenditure on regional $\mathrm{R} \& \mathrm{D}$ in the year $\mathrm{t}-1 . \delta$ represents the depreciation rate. Based on recent research results, $\delta$ is set at $15 \%$ in this paper.

4.2. Data Source. Formula (7) is obtained by combining recent research results, the characteristics noted in national industrial classification statistics, the status of Chinese high patent-intensive industries, and the relevant data of the report "Main Statistical Data Report of China's Patent Intensive Industries" issued by the State Intellectual Property Office.

The intensity of industrial invention patents equals the quotient of the total number of authorized invention patents in the industry within 5 years and the average number of employees in the industry within 5 years.

Formula (7) is as follows:

the intensity of industrial invention patents

$$
=\frac{\text { sum of authorized invention patents within } 5 \text { years }}{\text { average number of employees within } 5 \text { years }} .
$$

According to the concept of the intensity of industrial invention patents, the average value of patent intensity and the respective patent intensities of all Chinese industries are obtained by calculating the relevant data from 2007 to 2017, whereby the average values of patent intensity in 9 industries exceed those of all other national industries. The nine industries are pharmaceutical manufacturing; arts and crafts manufacturing; oil and gas exploration; electrical machinery manufacturing; chemical manufacturing; computers, communications, and other electronic equipment manufacturing; special equipment manufacturing; instrument manufacturing; and tobacco processing. According to the research content, the data related to patents from 2007 to 2017 are selected. Considering the cycle of patent outputs and achievements transformation, this paper sets the time lag as one year. Therefore, the output indicator data lag one year behind the input indicator data. Based on the 
TABLE 2: Technological innovation efficiency of 8 high patent-intensive industries in 2016.

\begin{tabular}{|c|c|c|c|}
\hline Industry & Tech $\mathrm{R} \& \mathrm{D}$ & Achi. trans & Efficiency \\
\hline Pharmaceutical manufacturing & 0.832 & 0.827 & 0.830 \\
\hline Crafts manufacturing & 0.954 & 0.897 & 0.926 \\
\hline Oil and gas exploration & 0.781 & 1.000 & 0.891 \\
\hline Electrical machinery manufacturing & 1.000 & 0.726 & 0.863 \\
\hline Chemical manufacturing & 0.704 & 0.802 & 0.753 \\
\hline Computer, communications, and other electronic equipment manufacturing & 1.000 & 1.000 & 1.000 \\
\hline Special equipment manufacturing & 0.911 & 0.764 & 0.838 \\
\hline Instrument manufacturing & 0.985 & 0.787 & 0.886 \\
\hline Mean value & 0.896 & 0.850 & 0.873 \\
\hline Standard deviation & 0.104 & 0.098 & 0.068 \\
\hline
\end{tabular}

accumulation of input, the input indicator is readjusted. The relevant data are obtained by referring to "China Statistical Yearbook (2007-2017)" and "China High-Tech Statistical Yearbook (2007-2017)."

4.3. Empirical Analysis. In this paper, the input and output indicator data are imported into Max DEA Pro 6.9 A software. The network relationship and unexpected output indicators are set, and the evaluation results are calculated and obtained. Then, the current status of the technical efficiency evaluation of high patent-intensive industries is further analyzed based on the evaluation results.

\subsubsection{Technical Efficiency Analysis of High Patent-Intensive} Industries. From the operation results for the innovation efficiency data of the eight industries in 2016 (Table 2), it can be observed that the average values of innovation efficiency in the stage of technology $\mathrm{R} \& \mathrm{D}$ and the stage of achievements transformation are 0.896 and 0.850 , respectively. These outcomes indicate that more attention is paid to resource inputs in the stage of technology $R \& D$ than in the stage of achievements transformation. In terms of total efficiency value, the average efficiency value of the eight high patent-intensive industries is only 0.873 , indicating a large margin for additional innovation efficiency improvement. However, the efficiency values among the industries are not balanced, and the differences are obvious. The efficiency values of certain industries are higher than those of others.

By observing the innovation efficiency values of each stage, we find that the average efficiency value of the technology $\mathrm{R} \& \mathrm{D}$ process is 0.896 and that the standard deviation is 0.104 . These outcomes indicate that although the original resource input is reduced by $10 \%$, the expected output level can still be achieved. The average efficiency value of high patent-intensive industries in the stage of achievements transformation is 0.850 , and the standard deviation is 0.098 . This value is lower than the average value of the total efficiency and the average efficiency value in the technology $\mathrm{R} \& \mathrm{D}$ stage. This result indicates that the low innovation efficiency of the achievements transformation stage affects the innovation efficiency of the entire industry.

As shown in the table, China's technology $\mathrm{R} \& \mathrm{D}$ is more stable than the transformation of achievements, and the national policy support and $\mathrm{R} \& \mathrm{D}$ procedures are more

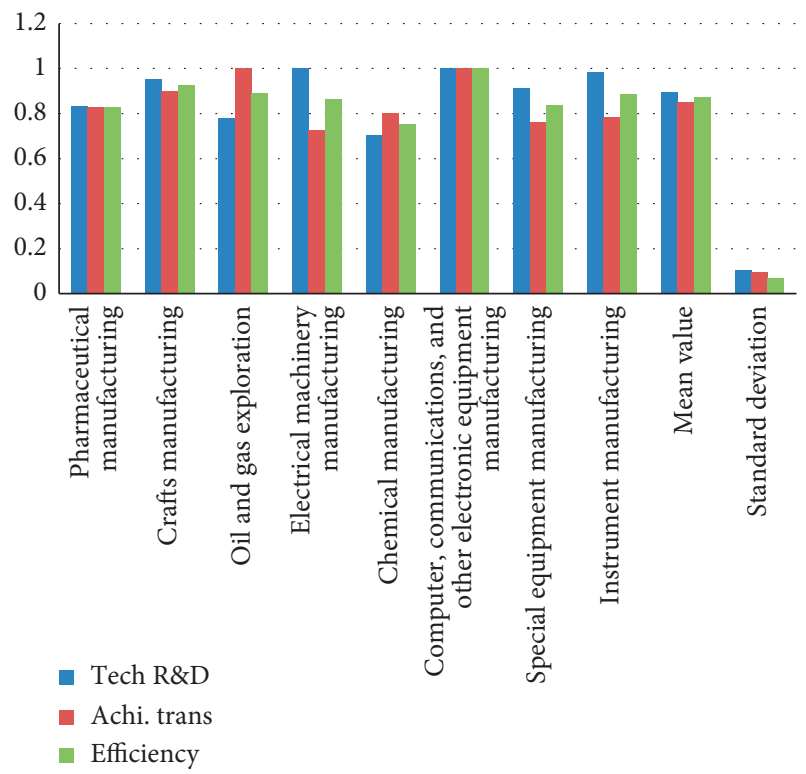

FIgURE 1: Technological innovation efficiency of 8 high patentintensive industries in 2016.

mature. However, the achievements transformation of Chinese high patent-intensive industries is far from sufficient. If the number of patent applications is valued and the transformation of achievements is ignored, the role of technology in economic development cannot be fully exploited, and the value of technological development is thus lost. In addition, the transformation of achievements is substantially affected by market factors. Good market and economic and financial environments are of substantial help to improve the transformation of achievements (Figure 1).

4.3.2. Analysis by Industry of Technical Efficiency of High Patent-Intensive Industries. Based on the data in Table 2, this paper analyzes the characteristics of the technology R\&D stage and the achievements transformation stage as well as the overall efficiency of 8 types of high patent-intensive industry in China in 2016. To further analyze these characteristics and determine the evolution path, this paper calculates the industry data of the 8 industry types from 2007 to 2018 and obtains the overall efficiency and the efficiency of 2 substages of technological innovation of these industries for the past 10 years (Table 3). 


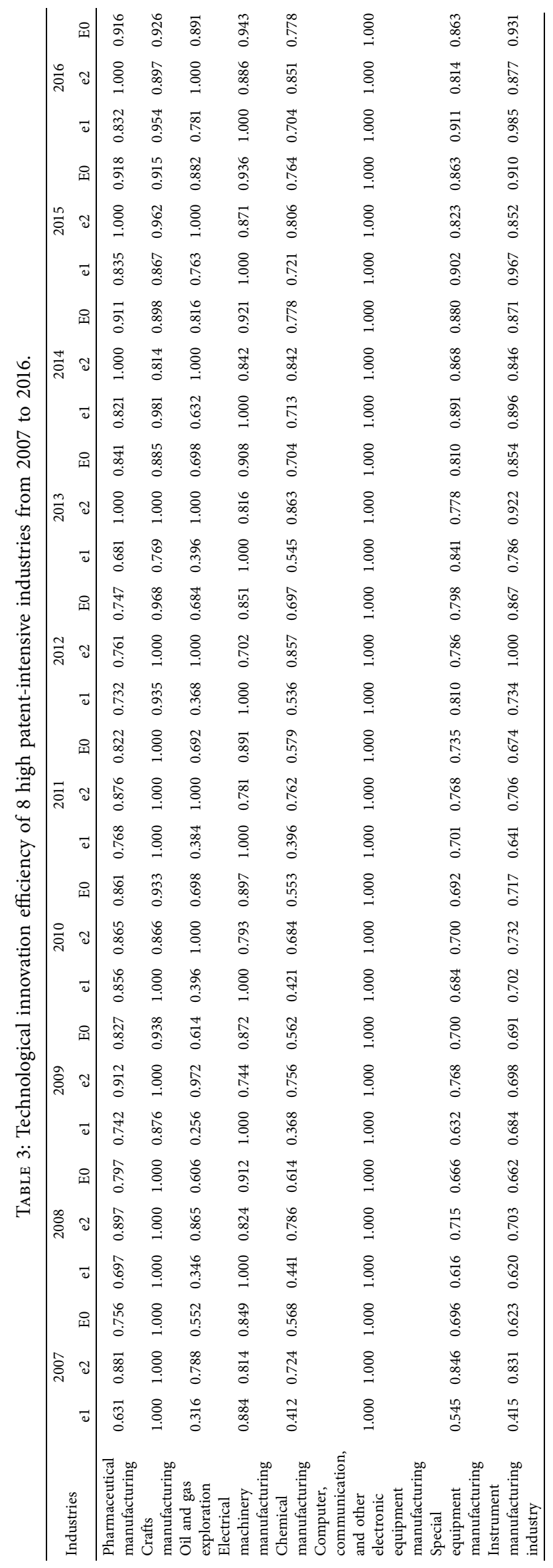




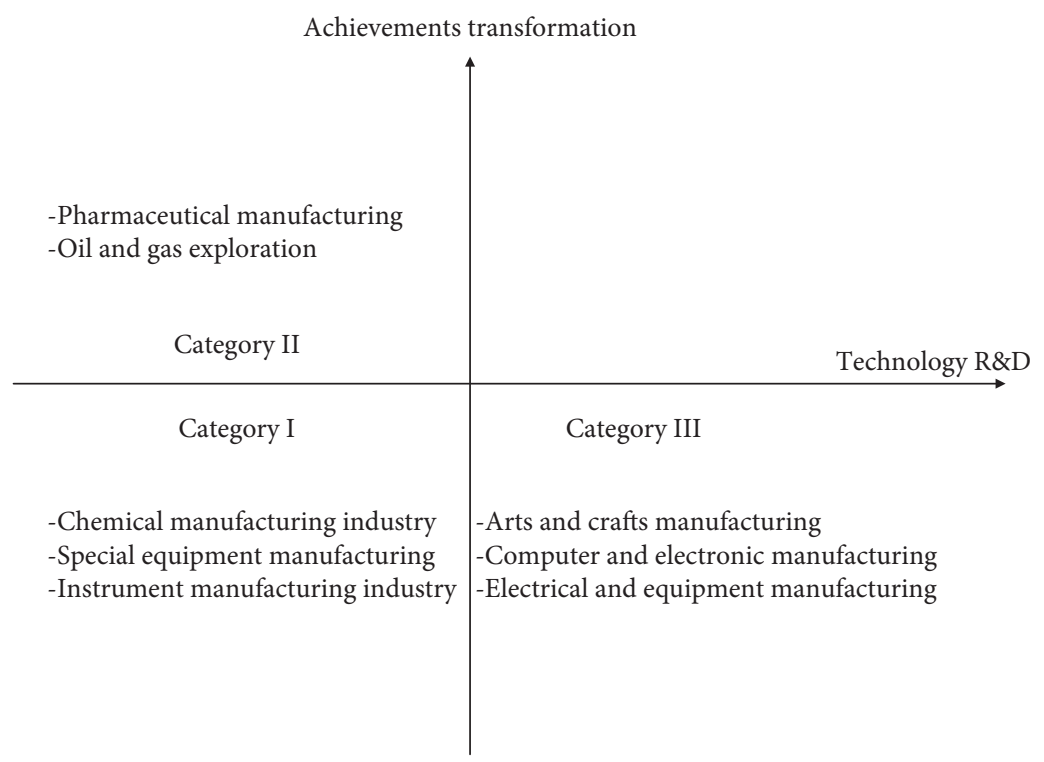

FIgURE 2: Technical efficiency of high patent-intensive industries.

The analysis by different industries reveals that the efficiency value of each industrial technology R\&D stage and achievements transformation stage fluctuates in accordance with the total efficiency fluctuation rule. The fluctuation of the efficiency value of the achievements transformation stage is much more obvious. The efficiency of the technology $R \& D$ stage of most industries is higher than that of the achievements transformation stage. It can be observed that achievements transformation remains the focus of high patent-intensive industries. Three industries display high efficiency in the technology $R \& D$ stage: handicraft manufacturing, computer and electronics manufacturing, and electrical equipment manufacturing. The efficiency of the technology R\&D stage in these industries is significantly higher than that of the achievements transformation stage, which indicates that the R\&D of these three industries has reached a higher level but that achievements transformation remains insufficient. In the process of technological innovation, particularly in the electrical equipment manufacturing industry, a disconnection remains between $\mathrm{R} \& \mathrm{D}$ and achievements transformation. The average achievements transformation efficiency value in the past ten years is only 0.807 , an outcome that requires further study and support. In pharmaceutical manufacturing and oil and gas exploration, the efficiency of achievements transformation is higher than that of technology R\&D. The respective average efficiency values of these two industries in the stage of achievements transformation are 0.919 and 0.963 , respectively. These outcomes indicate that the achievements transformation levels of these two industries are already high, reflecting the urgent social demand for the products of these two industries. The reason for the low overall innovation efficiency can be found in the low efficiency of the technology $R \& D$ stage. Therefore, it is imperative to strengthen technology $R \& D$ in these two industries. Low innovation efficiency occurs in two substages in chemical manufacturing, special equipment manufacturing, and instrument manufacturing. This outcome indicates that both technology R\&D and achievements transformation are insufficient in these three industries. Steps should be taken to increase inputs, address technical problems, and improve the level of achievements transformation. According to the efficiency values in Table 2, the 8 industries can be classified as follows (Figure 2):

Category I: industries with dual low innovation efficiency, i.e., low innovation efficiency both in technology $\mathrm{R} \& \mathrm{D}$ and in achievements transformation. These industries are chemical manufacturing, special equipment manufacturing, and instrument manufacturing.

Category II: industries with low-to-high level innovation efficiency, i.e., low innovation efficiency in technology R\&D and high innovation efficiency in achievements transformation. These industries are pharmaceutical manufacturing and oil and gas exploration.

Category III: industries with high-to-low level innovation efficiency, i.e., high efficiency in technology R\&D and low efficiency in achievements transformation. These industries are arts and crafts manufacturing, computer and electronics manufacturing, and electrical equipment manufacturing.

4.4. Research Deficiencies and Prospects. First, this paper is mainly based on the relevant theory of technological innovation efficiency while studying the innovation efficiency of high patent-intensive industries in China. In spite of the fact that complex relationship among different stages, time lag, resource accumulation, and other aspects are all considered, the disturbing factors that affect efficiency still need to be comprehensively dived in for further study. Secondly, the selected statistical data are based on "China Statistical Yearbook" and "China Statistics Yearbook on High Technology Industry," so the data are lagging. Thirdly, the mechanism and path of influencing factors on technological 
innovation need to be clarified. Next, scholars can carry out further research on technological innovation mechanisms, conduct in-depth enterprise researches, and conduct more targeted researches.

\section{Conclusions and Limitations}

Based on the above research, this paper starts from the innovation process and adopts SBM-NDEA to divide the technological innovation process into two stages: technology R\&D stage and achievement transformation stage, and conducts researches on both stages. According to the panel data of China high technology industry from 2007 to 2016, the technological innovation efficiency of high-patent intensive industries and subindustries was evaluated. The study believes that the overall technological innovation efficiency of China's high-patent intensive industries is gradually increasing. The technological R\&D efficiency has improved, but the rapid absorption and transformation of R\&D achievements are insufficient; the development of technological innovation efficiency in each subindustry is uneven, and the gap is relatively obvious.

It is suggested that the government departments should further promote collaborative innovation and coordinated development of industry, academia, and research; improve the market structure and give play to the market's guiding role in resource allocation and transformation of results; and increase intellectual property protection, increase government support for the industry, and promote the sustainable development of high patent-intensive industries.

\section{Data Availability}

The data used to support the findings of this study are available from the corresponding author upon request.

\section{Conflicts of Interest}

The authors declare that they have no conflicts of interest.

\section{Acknowledgments}

The research presented in this paper is part of a research project sponsored by the Youth Fund Project of the National Natural Science Foundation (71603048) and the National Social Science Fund (14BGL007).

\section{References}

[1] National Intellectual Property Administration, Catalogue of Patent-Intensive Industries, Intellectual Property Publishing House, Beijing, China, 2016.

[2] Z. Cha, China Statistics Yearbook on High Technology Industry, China Statistics Publishing House, Beijing, China, 2017.

[3] S. Siwek, Engines of Growth: Economic Contributions of the U.S. Intellectual Property Industries, Economists Incorporated, New York, NY, USA, 2006.

[4] M. Mazzucato and S. Parris, "High-growth firms in changing competitive environments: the US pharmaceutical industry
(1963 to 2002)," Small Business Economics, vol. 44, no. 1, pp. 145-170, 2015.

[5] S. N. Afriat, "Efficiency estimation of production functions," International Economic Review, vol. 13, no. 3, pp. 568-598, 1972.

[6] W. Li and F. Liu, "The comprehensive measurement of innovation efficiency of China's high-tech industry based on environmental factors," Science \& Technology Progress and Policy, vol. 36, no. 4, pp. 75-81, 2019.

[7] S. Liu, X. Jung, and Yu Qian, "Evolving law of technology innovation in high-tech industry of China," The Journal of Quantitative \& Technical Economics, vol. 32, no. 7, pp. 104116, 2015.

[8] Y. Hu and D. Chen, "Decomposition of total factor productivity growth rate in China's high-tech industries-a test for "the structural bonus hypothesis"” China Industrial Economics, vol. 2, pp. 136-154, 2019.

[9] B. Lee, E. Sohn, D. Won, W. Yeo, K. Kim, and S. Kim, "The efficiency analysis of national R\&D planning for the field of precision medicine in korea," Journal of Open Innovation: Technology, Market, and Complexity, vol. 4, no. 3, p. 39, 2018.

[10] K. Shin, E. Kim, and E. Jeong, "Structural relationship and influence between open innovation capacities and performances," Sustainability, vol. 10, no. 8, p. 2787, 2018.

[11] E. G. Carayannis, E. Grigoroudis, and Y. Goletsis, "A multilevel and multistage efficiency evaluation of innovation systems: a multiobjective DEA approach," Expert Systems with Applications, vol. 62, no. 1, pp. 63-80, 2016.

[12] M. Xu and N. Jiang, "The patent-intensive industries in China and the factors: an empirical study," Studies in Science of Science, vol. 222, no. 2, pp. 201-208, 2013.

[13] X.-F. Pan and Y. Yang, "Evaluation of industrial enterprise's innovation efficiency in China excluding the influence of environment variables," Operation Research and Management Science, vol. 23, no. 6, pp. 244-251, 2014.

[14] J. Han, "An empirical analysis on China's high-technology industry innovation efficiency based on SFA," Studies in Science of Science, no. 3, pp. 467-472, 2010.

[15] W. Chen, S. Rong, Y. Zhang, and S. Tian, "Evaluation research on the patent innovation efficiency of China's knowledge intensive industry based on DEA-malmquist index approach," Management Review, vol. 25, no. 8, pp. 39-45, 2013.

[16] Z. Feng and W. Chen, "R\&D innovation efficiency of Chinese high-tech industries-based on two-stage network DEA model with constrained resources," Systems Engineering-Theory and Practice, vol. 34, no. 5, pp. 1202-1212, 2014.

[17] N. Jiang, "Study on R\&D performance evaluation of patentintensive industries: based on DEA-malmquist index test," Science of Science and Management of S\&T, vol. 35, no. 3, pp. 99-107, 2014.

[18] Y. Hu and L. Zhou, "Research on the innovation efficiency and influencing factors of high-tech industry in the yangtze river economic belt," Journal of Industrial Technological Economics, vol. 6, no. 6, pp. 71-77, 2018.

[19] Y. Wen-jing, L.-H. Ma, and L. Hai-xia, "Innovation efficiency and factors of high-tech industry on two-stage series DEAbased methods," R\&D Management, vol. 27, no. 3, pp. 137146, 2015.

[20] Y.-Q. Bao, R.-Y. Lu, and X. Lin, "Study on innovation efficiency of China's LCD industry based on two-stage DEA model," Science of Science and Management of S.\&T.vol. 37, no. 9, pp. 49-57, 2016.

[21] S. Kang, "The efficiency evolution of high-tech industry's innovation value chain from the perspective of 
heterogeneity-A study based on the three stage DEA modified by SFA," Science and Technology Management Research, vol. 37, no. 6, pp. 7-1, 2017.

[22] J. Guan and K. Zuo, "A cross-country comparison of innovation efficiency," Scientometrics, vol. 100, no. 2, pp. 541-575, 2014.

[23] W. Liu, "Measurement on innovation efficiency of high-tech industries in China--Based on Three-stage DEA Model," Journal of Applied Statistics and Management, vol. 34, no. 1, pp. 17-28, 2015.

[24] K. Tone and B. K. Sahoo, "Cost efficiency and returns to scale in life insurance corporation of India using data envelopment analysis," GRIPS Research Report Series, p. 1, 2002.

[25] F. Liu and M. Deng, "The technology innovation efficiency analysis of yangtze river economic belt using PCA and SEDEA joint model," SciencedTechnology Progress and Policy, vol. 34, no. 23, pp. 48-51, 2017.

[26] H. Chen, P. He, C. Lin, and Z. Feng, "Study of technology of innovation efficiency of high patent intensity industry in China-based on SBM-NDEA model," Operation Research and Management Science, vol. 27, no. 3, pp. 191-199, 2018.

[27] R. Färe and S. Grosskopf, "Network DEA," Socio-Economic Planning Sciences, vol. 34, no. 1, pp. 35-49, 2000.

[28] Y. H. Chiu, J. C. Lin, C. C. Hsu, and J. W. Lee, "Carbon emission allowances of efficiency analysis: application of super SBM ZSG-DEA model," Polish Journal of Environmental Studies, vol. 22, no. 3, pp. 653-666, 2013.

[29] L. Sun, W. Chen, J. Liu, and Z. Yang, "Evaluation research on the technology innovation efficiency of China's patent-intensive industry based on DEA - malmquist index approach," Science and Technology Management Research, vol. 36, no. 19, pp. $52-55+69,2016$.

[30] Y. Yu, P. Wu, and J. Lin, “The R\&D efficiency of China's fractionized high technology industry based on the angle of value chain," Science of Science and Management of S.\&T, vol. 31, no. 5, pp. 60-65, 2010.

[31] N. Jiang, "Performance evaluation of innovation efficiency system of patent-intensive industries," Studies in Science of Science, no. 7, pp. 1003-1011, 2014.

[32] H. Fan and Zhou De-qun, "Regional science and technology innovation efficiency evolution and its affect factors in Chinese provinces," Science Research Management, no. 1, pp. 10-18, 2012.

[33] H. Liu, Y. Liu, and H. Qiao, "Research on technological innovation efficiency of strategic emerging industries in China," Systems Engineering-Theory \& Practice, no. 9, pp. 296-303, 2015.

[34] D. V. B. Guellec, "Pottelsberghe de la Potterie. From R D to productivity growth:do the institutional settings and the source of funds of R D matter?" Oxford Bulletin of Economics and Statistics, no. 3, 2004. 